\title{
Performing a Risk Analysis Study for Implementing a Biodiesel Plant
}

\section{Elgharbawy AS*}

Materials Science Department, Institute of Graduate Studies and Research (IGSR), Alexandria University, Egypt

*Corresponding author: Abdallah S Elgharbawy, Materials Science Department, Institute of Graduate Studies and Research (IGSR), Alexandria University, 163 Horrya Avenue, P.O. Box 832, Shatby, 21526, Alexandria, Egypt, Tel: 01004438671; Email: ab_pet_88@hotmail.com

\section{Case Report \\ Volume 5 Issue 1}

Received Date: January 13, 2021

Published Date: January 28, 2021

DOI: $10.23880 /$ ppej-16000248

\section{Abstract}

Risk as, an uncertain event, or condition that if it occurs, has a positive or negative effect on a project's objective. Risk analysis is done via interviews and brainstorming considering the available and extensive experience of the involved stakeholders. Each identified risk is prioritized through a qualitative risk analysis process considering the probability of occurrence and the impact by project stakeholders. The results of risk management planning processes are used to update/re-plan the project management plan to consider the risk effect on the project. The biodiesel project is very profitable, the economic indicators for the project are very high, and the execution of such a project will strengthen the national economy. Therefore, a biodiesel risk analysis is performed to achieve security for the plant. The depletion of fossil fuel forces the world to look for alternative ways for energy production. The most common way is the production of biodiesel from waste cooking oil. This paper presents a detailed cost analysis for a biodiesel plant with capacity 100,000 ton/year.

Keywords: Risk; Risk analysis; Biodiesel

\section{Introduction}

Business risk is the factors that a company or organization will face and will lower its profits or lead it to fail. Anything that threatens a company's ability to achieve its financial goals is considered a business risk [1]. In some cases, the cause of risk is external to a company. Because of this, it is impossible for a company to completely protect itself from risk. However, there are ways to mitigate the overall risks associated with operating a business; most companies accomplish this through adopting a risk management strategy [2,3].

Business risks arise from uncertainty about the profit of a commercial business due to unwanted events such as changes in tastes, changing preferences of consumers, strikes, increased competition, changes in government policy, obsolescence etc.. Business risks are controlled using techniques of risk management. In many cases, they may be managed by intuitive steps to prevent or mitigate risks, by following regulations or standards of good practice, or by insurance. Enterprise risk management includes the methods and processes used by organizations to manage risks and seize opportunities related to the achievement of their objectives [4,5]. Economically, biodiesel is more profitable than petro-diesel as biodiesel plants does not cost more money like refining plants, in addition low cost of biodiesel feedstock rather than expensive crude oil the feedstock of petro-diesel [6]. Production of biodiesel is a simple process that does need neither a license nor a complicated technology [7]. Environmentally, biodiesel is better as it does not contain sulfur so sulfur emissions is eliminated [8]. It is renewable as biodiesel is produced from renewable resources such as used cooking oil or biological organisms while petro-diesel made from finite sources $[9,10]$. 


\section{Petroleum \& Petrochemical Engineering Journal}

\section{Definitions}

- Risk Assessment: a systematic investigation and analysis of potential risks, combined with the assignment of severities of probabilities and consequences. These are used to rate risks in order to prioritize the mitigation of high risks.

- Risk: A negative effect of uncertainty.

- Opportunity: A positive effective of uncertainty

- Risk Mitigation: a plan developed with the intent of addressing all known or possible risks and preventing their occurrence.

- Interested parties: Institutions and individuals who may influence or be influenced by operations of the organization.

\section{Risk Analysis for Biodiesel Plant}

Table 1 shows the risk analysis applied to predict the risk of biodiesel plant. Table 2 explains the risk characteristics. Table 3 describes the probability of event. Table 4 describes the impact of risk.

\begin{tabular}{|c|c|c|c|c|c|}
\hline Category & Risk & Prob. & Impact & $\begin{array}{c}\text { Risk } \\
\text { Value } \\
\end{array}$ & $\begin{array}{c}\text { Accept } \\
\text { risk }\end{array}$ \\
\hline Operation and Maintenance & Large scale oil/ Fluid spill incident in populated area & 3 & 4 & 12 & $\mathrm{Y}$ \\
\hline Operation and Maintenance & Small-medium scale oil spill incident in populated area & 5 & 2 & 10 & $\mathrm{Y}$ \\
\hline HSE & High LEL & 4 & 4 & 16 & $\mathrm{~N}$ \\
\hline Operation and Maintenance & Internal corrosion & 3 & 3 & 9 & $\mathrm{~N}$ \\
\hline Construction & Construction accident & 2 & 4 & 8 & $\mathrm{Y}$ \\
\hline Construction & New construction activities affecting existing pipeline & 4 & 2 & 8 & $\mathrm{~N}$ \\
\hline Force Majeure & Major earthquake & 2 & 4 & 8 & $\mathrm{~N}$ \\
\hline Operation and Maintenance & Increased tanker traffic & 4 & 2 & 8 & $\mathrm{~N}$ \\
\hline Design & Land use and acquisition risk & 2 & 3 & 6 & $\mathrm{~N}$ \\
\hline Financial & Interest rate risk & 3 & 2 & 6 & $\mathrm{~N}$ \\
\hline Labor risks & Operational accident & 2 & 3 & 6 & $\mathrm{~N}$ \\
\hline Operation and Maintenance & External corrosion & 3 & 2 & 6 & $\mathrm{~N}$ \\
\hline Operation and Maintenance & Large scale oil spill incident in unpopulated area & 3 & 2 & 6 & $\mathrm{~N}$ \\
\hline Financial & Defaulting on debt (bonds) & 1 & 5 & 5 & $\mathrm{~N}$ \\
\hline Operation and Maintenance & Small-medium scale oil spill incident in unpopulated area & 5 & 1 & 5 & $\mathrm{~N}$ \\
\hline Construction & Inferior quality materials or equipment & 1 & 4 & 4 & $\mathrm{~N}$ \\
\hline Construction & Ground composition/unstable ground & 1 & 4 & 4 & $\mathrm{~N}$ \\
\hline Construction & Erosion - Mudslide - Landslides & 1 & 4 & 4 & $\mathrm{~N}$ \\
\hline Construction & Fire in construction site & 1 & 4 & 4 & $\mathrm{~N}$ \\
\hline
\end{tabular}

Table 1: Project Risk Register.

- Y: the risk is accepted

- $\mathrm{N}$ : the risk is not accepted.

\begin{tabular}{|c|c|c|}
\hline Category & Name & Characteristics \\
\hline 5 & Catastrophic & $\begin{array}{c}\text { Disastrous impact on success of the project. Debilitating financial and temporal impact. Certain } \\
\text { injuries or fatalities }\end{array}$ \\
\hline 4 & Critical & $\begin{array}{l}\text { Considerable impact on success of the project. Major financial and temporal impact. Probable } \\
\text { injuries or fatalities. }\end{array}$ \\
\hline 3 & Significant & $\begin{array}{c}\text { Noticeable impact on success of the project. Significant financial and temporal impact. Possible } \\
\text { injuries or fatalities. }\end{array}$ \\
\hline 2 & Minor & $\begin{array}{c}\text { Minimal impact on success of the project. Some financial and temporal impact. No injuries or } \\
\text { fatalities. }\end{array}$ \\
\hline 1 & Negligible & $\begin{array}{l}\text { No impact on success of the project. No damage to the system. No injuries or fatalities. } \\
\text { Negligible financial impact. }\end{array}$ \\
\hline
\end{tabular}

Table 2: risk characteristics 


\section{Petroleum \& Petrochemical Engineering Journal}

\begin{tabular}{|c|c|c|}
\hline Category & Name & Characteristics \\
\hline 5 & Very high & Almost certain to occur \\
\hline 4 & High & Can be expected to occur in the life of the project \\
\hline 3 & Medium & As likely to occur as not occur \\
\hline 2 & Low & May occur occasionally \\
\hline 1 & Very low & Unlikely to occur, but possible \\
\hline
\end{tabular}

Table 3: probability of event.

\begin{tabular}{|c|c|c|c|c|c|}
\hline Probability & $\mathbf{1}$ & $\mathbf{2}$ & $\mathbf{3}$ & $\mathbf{4}$ & $\mathbf{5}$ \\
\hline 5 - Very high & & & & & \\
\hline 4- High & & & & & \\
\hline 3 - Medium & & & & & \\
\hline 2 - Low & & & & & \\
\hline 1 - Very low & & & & & \\
\hline
\end{tabular}

Table 4: Risk Impact.

\section{Conclusion}

Explored the range of risks that organizations may be exposed. We have not only introduced ourselves to the main financial risks but also to the other risks which may indirectly impact on the finances of organizations - such as operational, reputational and legal and regulatory risk. Examined how the process of risk management should be implemented within organizations - thereby providing the structure for examining each type of financial risk in detail. It is important that the individual risks be not looked at entirely in isolation from each other. Doing so is what is known as a silo approach to risk management. Instead, managers must develop a holistic view of risk. Organizations may have small exposures to the individual risks, but when these are aggregated, they may have, in total, substantial financial and non-financial risks that require careful management. What we do certainly know - given the recent catalogue of highprofile financial calamities-is that the failure to manage risks can have devastating and, on occasion, terminal outcomes for organizations.

\section{References}

1. Kaplan RS, Norton DP (1996) The Balanced Scorecard: Translating Strategy into Action. Harvard Business School Press, Boston MA, USA.

2. Kaplan RS, Norton DP (2000) The Strategy-Focused Organization: How Balanced Scorecard Companies Thrive in the New Business Environment. Harvard Business School Press, Boston, USA.

3. Kaplan RS, Norton DP (2008) The Execution Premium:
Linking Strategy to Operations. Harvard Business School Press Boston MA, USA.

4. Wheelen TL, Hunger JD (2012) Strategic management and business policy towards global sustainability. $13^{\text {th }}$ (Edn.), Boston, Library of Congress Cataloging-inPublication Data.

5. Elgharbawy ASAA (2018) Review on Corrosion in Solar Panels. International Journal of Smart Grid-ijSmartGrid 2(4): 218-220.

6. Elgharbawy A, Sayed A (2020) Production of biodiesel from used cooking using linear regression analysis. Journal of Petroleum and Mining Engineering 22(2): 9299.

7. El-Gharbawy ASAA (2016) Production Of Biodiesel From Non Edible Vegetable Oil.

8. Akubude V, Nwaigwe K, Dintwa E (2019) Production of biodiesel from microalgae via nanocatalyzed transesterification process: A review. Materials Science for Energy Technologies 2(2): 216-225.

9. Elgharbawy AS, Sadik WA, Sadek OM, Kasaby MA (2021) Glycerolysis treatment to enhance biodiesel production from low-quality feedstocks. Fuel 284: 118970.

10. Elgharbawy ASA (2017) Cost analysis for biodiesel production from waste cooking oil plant in Egypt. International Journal of Smart Grid-ijSmartGrid 1(1): 16-25.

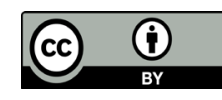

